DR JULIA MORPHET (Orcid ID : 0000-0001-7056-6526)

PROFESSOR JULIE CONSIDINE (Orcid ID : 0000-0003-3801-2456)

Received Date : 07-Jun-2016

Revised Date : 04-Jan-2017

Accepted Date : 25-Jan-2017

Article type : Original Research: Empirical research - mixed methods

\title{
A FRAMEWORK FOR TRANSITION TO SPECIALTY PRACTICE PROGRAMS
}

Running Head: A framework for transition to specialty practice programs

Dr Julia MORPHET, RN, $\mathrm{PhD}^{1}$, Associate Professor Virginia PLUMMER, RN, PhD², Professor Bridie KENT, RN, $\mathrm{PhD}^{3}$, Professor Julie CONSIDINE, RN, $\mathrm{PhD}^{4}$,

1. Senior Lecturer, Nursing \& Midwifery, Monash University.

2. Associate Professor Nursing Research, Monash University and Peninsula Health

3. Professor in Leadership in Nursing, School of Nursing and Midwifery, Faculty of Health and Human Sciences, Plymouth University

4. Professor, Deakin University, School of Nursing and Midwifery / Eastern Health Deakin University Nursing \& Midwifery Research Centre / Deakin University, Centre for Quality and Patient Safety Research

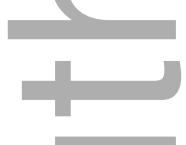

Corresponding author: Julia Morphet, Nursing \& Midwifery, Monash University, McMahons Road, Frankston, Victoria, 3199. Ph 039904 4032, email: Julia.morphet@monash.edu Twitter: @juliamorphet

This is the author manuscript accepted for publication and has undergone full peer review but has not been through the copyediting, typesetting, pagination and proofreading process, which may lead to differences between this version and the Version of Record. Please cite this article as doi: 10.1111/jan.13279

This article is protected by copyright. All rights reserved 


\section{CONFLICT OF INTEREST STATEMENT}

No conflict of interest has been declared by the authors.

\section{FUNDING}

This study was supported by the Annie M Sage scholarship, Australian College of Nursing, and the Betty Jeffrey Award and scholarship, Nurses Memorial Centre.

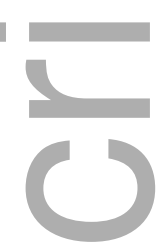

ABSTRACT

Aim

To develop a framework for emergency nursing transition to specialty practice programs.

\section{Background}

Transition to Specialty Practice programs were introduced to fill workforce shortages and facilitate the transition of nurses to specialty nursing practice. These programs are recognised as essential preparation for emergency nurses. Emergency nursing Transition to Specialty Practice programs have developed in an ad hoc manner and as a result, program characteristics vary. Variability in program characteristics may result in inconsistent preparation of emergency nurses.

\section{Design}

Donabedian's Structure-Process-Outcome model was used to integrate results of an Australian study of emergency nursing Transition to Specialty Practice programs with key education, nursing practice and safety and quality standards to develop the Transition to Specialty Practice (Emergency Nursing) Framework.

\section{Methods}

An explanatory sequential design was used. Data were collected from 118 emergency departments over 10 months in 2013 using surveys. 13 interviews were also conducted. Comparisons were made using Mann Whitney U, Kruskal Wallis and Chi-Square tests. Qualitative data were analysed using content analysis. 
Results

Transition to Specialty Practice programs were offered in 80 (72.1\%) emergency departments surveyed, to improve safe delivery of patient care. Better professional development outcomes were achieved in emergency departments which employed participants in small groups (Median=4 participants) and offered programs of 6 months duration. Written assessments were significantly associated with articulation to postgraduate study (Chi Square Fisher's exact $p=<0.001$ ).

\section{Conclusion}

The Transition to Specialty Practice (Emergency Nursing) Framework has been developed based on best available evidence to enable a standardised approach to the preparation of novice emergency nurses.

\section{Key words:}

emergency nursing, professional development, workforce issues, mixed method design, transition program, preparation.

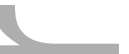

\section{SUMMARY STATEMENT}

\section{Why is this research or review needed?}

- Transition to Specialty Practice programs are used internationally to provide essential preparation for novice emergency nurses.

- The literature reveals significant variability in program characteristics.

\section{What are the key findings?}

- Transition to Specialty Practice programs were widely available in Australian emergency departments.

- Variations in the design and delivery of Transition to Specialty Practice programs resulted in inconsistent outcomes for the nursing workforce and the organisation. 
- Professional development outcomes were optimised when Transition to Specialty Practice programs were of 6-months duration and employed participants in small groups.

\section{How should the findings be used to influence policy/practice/research/education?}

- The Transition to Specialty Practice (Emergency Nursing) Framework was designed to optimise participant and organisational outcomes and provides an evidence-based approach for consistent preparation of novice emergency nurses.

- The Transition to Specialty Practice (Emergency Nursing) Framework should be evaluated against patient safety and quality of care outcomes.

The Transition to Specialty Practice (Emergency Nursing) Framework should be used as a benchmark against which existing Transition to Specialty Practice programs can be benchmarked.

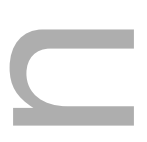

\section{INTRODUCTION}

Transition to Specialty Practice (TSP) programs provide a structured, supported transition for nurses entering a nursing specialty (Boyle et al. 2008) and are used in emergency departments (EDs) internationally to improve recruitment, retention and preparation for practice (Table 1). The consensus in the international literature is that emergency nursing TSP programs prepare participants to be 'fit for practice' as a beginning emergency nurse (Considine and Hood 2004, Jarman and Newcombe 2010, Loiseau et al. 2003, Patterson et al. 2010).

Emergency nursing TSP programs have developed in an ad hoc, autonomous manner. Some TSP programs were reportedly based on Benner's (1984) 'Novice to Expert' theoretical framework (Alban et al. 1999, Glynn and Silva 2013, Kidd and Sturt 1995, KingsnorthHinrichs 2009, Truman 2004, Winslow et al. 2009, Wolf 2005), while many TSP programs had no consistent framework used to guide their development or delivery. As a result, there are significant variations in the way TSP programs are delivered. TSP programs have varied in duration from five weeks (Kidd and Sturt 1995) to two years (Kingsnorth-Hinrichs 2009). Many TSP programs targeted Registered Nurses (RNs) with 1-2 years nursing experience post qualification, yet many also employed newly graduated RNs (Table 1). 
Support for TSP program participants has also been provided in different ways. Most programs relied on didactic teaching as the primary method of providing theoretical preparation for practice (Alban et al. 1999, Considine and Hood 2004, Morphet et al. 2008). Some programs also used simulation (Kingsnorth-Hinrichs 2009, Truman 2004), case scenarios (Gurney 2002, Kingsnorth-Hinrichs 2009, Sweeney 2010, Truman 2004), skills labs (Patterson et al. 2010, Truman 2004, Zavotsky 2000) and online learning (Patterson et al. 2010). One TSP program relied solely on preceptorship to support participants (Betts 2003), while many TSP programs combined preceptorship and theoretical preparation (Table 1).

Emergency nursing TSP programs are commonly completed by RNs prior to enrolment in postgraduate study (Morphet et al. 2015). In addition, many TSP program graduates are provided with formal articulation into postgraduate university studies (Morphet et al. 2015), yet inconsistencies in TSP program characteristics and delivery, mean that TSP program graduates were not educationally or clinically prepared to the same level. In 2002, an Australian review of nursing education (Heath 2002) recommended the development of a TSP framework to improve consistency in graduate preparation. To date, this has not been developed, yet there is a clear need for a framework guiding the structure, process and outcome of TSP programs, to achieve consistent development of knowledge and skills for beginning emergency nurses and rigorous formal articulation into postgraduate study. In this paper, the development of an evidence-based framework for emergency nursing TSP programs will be presented.

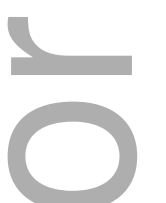

\section{BACKGROUND}

This study aimed to develop a framework for emergency nursing TSP programs. Quantitative and qualitative TSP program data were collected from 80 EDs around Australia, using online surveys and face to face interviews. Data were integrated and analysed, to identify program characteristics that resulted in best outcomes. Donabedian's (1988) Structure-Process-Outcome framework was the overarching framework underpinning the study, however data integration was also informed by several key education frameworks, nursing practice and safety and quality standards. The theoretical constructs that were used in this study are outlined in the following section.

\section{Structure-Process-Outcome Model}


Donabedian's Structure-Process-Outcome model was selected to provide the theoretical underpinning of the TSP (Emergency Nursing) Framework, because it is able to encompass the setting and resources where the TSP program would be offered (structure), the processes in the TSP program (process) and the functions of the TSP program (outcomes) (Donabedian 1988).

\section{Educational Theory}

Benner's Novice to Expert (1984) model was selected as the educational framework for the TSP (Emergency Nursing) Framework. In the Novice to Expert model, a learner passes through five levels of development of skills and knowledge: novice; advanced beginner; competent; proficient; and expert (Benner 1984). These different levels reflect progression from a reliance on theoretical principles and rule driven behaviours, to the use of previous experiences to develop knowledge and solve problems. Benner's model is suitable for the TSP program as it is based on the premise that expertise is context specific (Benner 1984) and therefore supports the clinical progression of participants.

In the $\mathrm{ED}$, clinical progression (the advancement from an area of lower patient acuity, to an area of higher patient acuity) is an important professional development outcome. Clinical progression in the ED follows a hierarchy of patient acuity (Figure 1). Patients with minor illness or injury generally have single system issues, with no or one comorbidity and have a low likelihood of life threatening clinical deterioration. The nursing care required generally has a low level of complexity of decision-making and decisions carry a low level of risk. Examples of patients with minor illness or injury include patients with soft tissue injury or flu-like illness.

Patients with moderate illness or injury may have single or multiple system issues in a patient with one or more comorbidities or risk of life-threatening clinical deterioration. Nursing care required has a moderate level of complexity of decision-making and decisions carry a moderate level of risk. Examples of patients with moderate illness or injury include patients with abdominal pain, chest pain, or shortness of breath.

Patients with critical illness or injury have multiple system issues in a patient with one or more comorbidities and a high likelihood of life-threatening clinical deterioration. The nursing care required has a high level of decision-making complexity and decisions carry a high level of risk. Examples of patients with critical illness or injury include patients with cardiac arrest or major trauma. These patients are usually cared for in the resuscitation cubicles. 
Using Benner's model (1984), TSP program participants commence as novice emergency nurses and develop knowledge and skills to advance through the five levels of proficiency caring for patients with minor illness or injury, before progressing to care for patients with moderate illness or injury, where they will once again be a novice.

\section{Education Standards}

Nursing education in Australia is governed by both the Nursing and Midwifery Board of Australia, an agency under the Australian Health Practitioner Regulation Agency (AHPRA) (AHPRA, 2015) and the Australian Qualifications Framework (AQF). The AQF underpins all regulated education at University and vocational levels and provides a guide to the volume of learning and expected learning outcomes required in all regulated education, ranging from Senior Secondary School Certificates to Doctoral Degrees (AQFC, 2013). The provision of clear guidelines in the AQF regarding the level of content, assessment and expected outcomes, enables consistency and standardisation in the delivery and assessment of education in nursing. A Bachelor of Nursing qualification sits at Level 7 of the AQF and graduates will have broad and coherent knowledge and skills for work in a professional context. Formal postgraduate qualifications in nursing undertaken in the tertiary sector, for example a Graduate Certificate or Graduate Diploma, are underpinned by Level 8 of the AQF (AQFC, 2013). At Level 8 of the AQF, graduates will have advanced knowledge and skills for work in a professional context. For TSP programs to articulate to postgraduate study and for graduates to be eligible for recognition of prior learning at Graduate Certificate or Graduate Diploma level, it was imperative that the TSP (Emergency Nursing) Framework should meet the requirements of Level 8 of the AQF.

\section{Nursing Practice Standards}

Nursing practice in Australia is governed by several standards. The Registered Nurse Standards for Practice (Nursing and Midwifery Board of Australia 2016) outline the standards by which all RNs are required to practice. The National Safety and Quality Health Service Standards underpin accreditation of all acute care hospitals in Australia and aim to improve the safety and quality of care delivery and minimise risks, particularly in relation to medication errors, patient deterioration, clinical handover, pressure injuries, falls and hospital acquired infections (Australian Commission on Safety and Quality in Health Care 2011). Emergency nursing practice is also guided by the College of Emergency Nursing Australasia (CENA) Practice Standards for the Emergency Nursing Specialist (CENA Practice Standards), which outline nine domains of professional practice for emergency nurses 
(CENA, 2013). Each of these standards were integrated either implicitly or explicitly in the TSP (Emergency Nursing) Framework.

\section{METHOD}

\section{Aim}

The aim of this study was to develop a framework for emergency nursing transition to specialty practice programs.

\section{Design}

An explanatory sequential design was used in this study. Quantitative data were collected from ED Nurse Managers and Nurse Educators via online surveys, to identify what (if any) TSP programs were being offered and to explore the characteristics and outcomes of the TSP programs. Following analysis of the quantitative data, Nurse Managers and Nurse Educators were interviewed to provide context and give meaning to the quantitative results (Creswell 2009, Teddlie and Tashakkori 2009). Study results were integrated with key education, nursing practice and safety and quality standards (described previously), to develop the TSP (Emergency Nursing) Framework.

\section{Sample}

There were 183 public EDs in Australia (Australian Institute of Health \& Welfare [AIHW], 2010). Most EDs treated both adults and children. At the time of the study, there was an average of 34,645 patients treated in each ED (National Health Performance Authority 2013). EDs which treated less than 5,000 patients in the 2010-2011 year $(n=19)$ or treated a specific patient population $(n=13)$ (AIHW, 2011), were excluded from the sample as they were not considered homogenous, leaving 151 EDs.

\section{Ethical considerations}

Ethics and research governance approval were obtained from 140 hospitals around Australia and the EDs at those hospitals were included in the sample.

\section{Data collection}

Two surveys were used to collect quantitative data from Nurse Managers and Nurse Educators throughout 2013. Details of survey implementation are described elsewhere (references omitted per journal guidelines, 2015, 2016). The surveys required participants to identify their employing hospital, to enable corresponding Nurse Manager and Nurse Educator data to be matched by organisation and aggregated. Nurse Managers provided data 
about the ED and staffing profile (number of treatment spaces, rostered nursing hours and nurses' qualifications). Nurse Educators provided data about the TSP program and emergency nursing education. TSP program characteristics including the provision of clinical preparation time (orientation, supernumerary time and clinical support), study days, mode of content delivery, TSP program duration and access to learning resources were also examined.

Nursing professional development was measured in terms of the reported clinical progression of TSP program participants and the percentage of emergency nurses in the ED who: i) had completed a relevant postgraduate qualification; or ii) were employed in Clinical Specialist positions. These outcomes were deemed to reflect the level of professional development of the nursing team in the ED. A graduate certificate or higher level of qualification in emergency nursing or critical care was considered a relevant postgraduate qualification. An emergency Clinical Specialist is an RN with a high degree of knowledge, skill and clinical decision-making in emergency nursing (New South Wales Health 2011).

\section{Data analysis}

Where possible, the survey completed by a Nurse Manager was matched to the survey completed by a Nurse Educator at the same hospital. A numeric identification number was then assigned to each ED for data analysis so that individual EDs could not be identified. The Statistical Package for Social Sciences (SPSS) V.20 (IBM Corporation 2012) was used to analyse quantitative data. TSP characteristics were described using descriptive statistics. Comparisons between TSP characteristics (e.g. mode of content delivery, duration) and professional development outcomes were undertaken using non-parametric statistics (Polit and Beck 2014). Specifically, the Chi-Square test for Independence was used to examine relationships between TSP characteristics and credit towards postgraduate study (categorical variables) (Pallant 2013, Schneider et al. 2013). Fisher's Exact Test was used when expected frequencies were less than five in one cell or more (Pallant 2013). The Mann Whitney U test was used to explore associations between categorical TSP characteristics (e.g. TSP duration) and nursing professional development outcomes (continuous variables). The Kruskall Wallis test was used to explore associations between three or more categorical TSP characteristics (e.g. categories of clinical preparation days) and professional development outcomes (Brace et al. 2003). Statistical significance was indicated by $p<0.05$ (Polit and Beck 2014). Content analysis was used for qualitative data (Polit and Beck 2014). Codes were allocated to interviewees to differentiate between participants. For example, NE 2 indicates that the second interview was with a Nurse Educator and NM 3 indicates that the third interview was 
with a Nurse Manager. Quantitative and qualitative data were analysed separately and then integrated.

\section{Study Rigour}

The surveys used in this study were adapted with permission from the 'Transition to Intensive Care Nursing, Survey of Existing Education/Transition Programs and Resources' survey (Boyle et al. 2008). Face and content validity were established by a panel of expert emergency nurse researchers. The surveys were then piloted by six people who held positions like those who would complete the survey. These respondents understood that they were informing the survey design (declared testing). Results at this stage confirmed survey reliability, with similar results repeated (Schneider et al. 2013).

Qualitative data were independently analysed by two members of the research team. The credibility and dependability of the findings was facilitated by discussions among the researchers, comparing and discussing the emerging themes and reaching consensus (Schneider et al. 2016). The identification of similar findings in each interview, which confirmed quantitative results, further enhanced the credibility of this study.

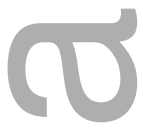

\section{RESULTS}

In this section, the results of the study will be presented, followed by the development of the TSP (Emergency Nursing) Framework. Surveys were sent to the Nurse Manager and Nurse Educator at each ED (140 EDs, 280 surveys). 65 Nurse Managers and 100 Nurse Educators completed the surveys, which provided data on 118 EDs (Figure 2). Thirteen interviews were conducted with Nurse Managers $(n=6)$ and Nurse Educators $(n=7)$ from different EDs. Interviewees worked in Victoria $(n=5)$, New South Wales $(n=3)$, Queensland $(n=3)$, Australian Capital Territory $(n=1)$ and South Australia $(n=1)$. Interviewees had a median of 14 years of experience in emergency nursing (IQR 12-18.5 years). The-Nurse Managers had a median of 4.5 years of management experience (IQR 1.89.8 years). The Nurse Educators had a median of 5 years of education experience (IQR 3.57.0 years).

\section{Transition to Specialty Practice Programs}

TSP programs were offered in most of the EDs $(n=80,72.1 \%)$ and were conducted once $(n=22,35.5 \%)$ or twice $(n=26,41.9 \%)$ per year $($ Median $=2, I Q R=1-2)$. TSP programs were introduced to improve patient safety and delivery of care. Nurse Educators reported concerns about patient harm and reduced quality of emergency nursing care when 
novice emergency nurses were employed into the ED without the TSP program. 'Coming into a very busy ED, it puts a lot of pressure on them ... how they cope, how they survive' (NE 2). 'The fast pace of the ED makes it difficult for inexperienced nurses to think critically, instead they become focused on tasks. Emergency's all about the undiagnosed patient and working out the puzzle of it, but I don't think it happens early on, just because of the pace of emergency nursing' (NE 6).

The TSP program was identified as mitigating these risks: 'the staff are better prepared and the patients benefit from that' (NE 8). 'It's about safe practice, knowing that you have people working in the areas [who] understand what they are doing' (NE 2).

TSP program participants were employed in groups, with up to 20 participants per intake (Median $=4, I Q R=3-8)$. Employing participants in a group made it easier for Nurse Managers and Educators to ensure participants received a consistent message 'I know that these 10 [participants] are all going to get the same message ... and the same level of support' (NM 3). Commencing participants in groups was also reported to provide peer support to and 'camaraderie among participants' (NM 13). 'They really support each other ... they become good friends and support each other through' (NE 6).

TSP programs were most commonly offered to RNs with 1-2 years of nursing experience $(n=63,80.8 \%)$. RNs with more than 2 years nursing experience $(n=41,52.6 \%)$ and new graduate nurses $(n=38,48.7 \%)$ were also recruited to programs. TSP programs ranged from 1-36-months duration (Median $=12$ months, $I Q R=5-12$ months). Mann Whitney $U$ tests showed that EDs with programs of 6-months duration had a higher percentage of nurses who held a relevant postgraduate qualification (43.8\%) and a significantly higher percentage of Clinical Specialist staff (18\%) than EDs with programs that were 12 -months duration $(30.8 \%, p=0.09 ; 9.8 \%, p=0.03$ respectively).

Theoretical preparation was facilitated via paid study days (lectures, tutorials, simulation) $(n=53,81.5 \%)$, self-directed learning packages $(n=51,78.5 \%)$, or a combination of each $(n=46,70.8 \%)$. There was a median of 5 study days (equivalent 40 hours) per program (IQR = 2-6 days). There was no major difference in the content delivered between TSP programs when compared by duration (6 \& 12 months). However, programs with study days, incorporated substantially more content than programs which were entirely self-directed.

Each TSP program participant was provided with a median of 12 clinical preparation shifts $(I Q R=7-22)$. The number of clinical preparation days provided seemed to be associated with professional development outcomes. EDs with TSPs which had 10-12 days of 
clinical preparation time had a slightly higher percentage of nurses with a relevant postgraduate qualification (34.5\%) and a greater percentage of Clinical Specialist staff (19.9\%), than EDs with either 1-9 days of clinical preparation time (respectively 33.3\%; $15.6 \%$ ) or $13+$ days of clinical preparation time (respectively $23.5 \%$; 6.7\%). A Kruskal Wallis test showed that these differences were not statistically significant (respectively $p=$ 0.63 and $p=0.18$ ).

Most Nurse Educators reported that clinical $(n=52,86.7 \%)$ or written $(n=38,63.3 \%)$ assessments were used in the TSP program. Assessments were reported to be beneficial to both staff and management. In some instances, assessments meant the participant could be deemed competent to undertake their own clinical tasks (for example insert intravenous cannula). 'Assessments give you confidence that they [participants] actually know what they're doing' (NE 12). Assessment also formed the basis for appraisals: 'I think they [participants] probably don't understand the importance of having a proper feedback process, but from an educator perspective that's vital' (NE 5). Chi Square test for Independence showed that there was a significant association between written assessments and credit towards postgraduate study (exact $p=<0.001$ ), with more than half of the TSPs with written assessments being awarded credit towards postgraduate study $(n=22,57.9 \%)$, while only one TSPP without a written assessment (4.5\%) was reported to be awarded credit towards postgraduate study.

Most Nurse Managers and Nurse Educators agreed that organisations wanted 'bang for their buck' from the participants and therefore participants should be able to work in a supported role in the resuscitation cubicles, caring for critically ill patients, by completion of the TSP program (NM 3, 9, 11, NE 1, 2, 5, 12). 'There was discussion last year, that if we're going to put those resources in, they [participants] should be progressing quickly' (NE 8). 'As a rule, we try to get them through to that resus [resuscitation] level' (NE 2). This end-point was not adjusted to reflect the participants' entry level experience.

TSP programs were reported to increase the rate of clinical progression among participants. 'They're getting in there [resuscitation] quicker and definitely with more knowledge behind them' (NE 12). TSP program graduates were also considered more likely to enrol in postgraduate study. Two reasons were provided for this. Participants were reported to be better prepared for postgraduate study: 'They get used to the review by the educators, they get used to meeting as a group and discussing clinical issues and at the point they go into the postgraduate program, the leap is not huge' (NM 13). 'Preparedness for postgrad [study] seems to be better [in the TSP cohort], we've had that feedback from a lot of postgrads ... 
they feel like doing the TSP helped them be prepared' (NE 8). In addition, half of the interviewees reported that TSP program credit into postgraduate programs provided a stimulus for many participants to enrol in postgraduate study (NUM 1, 3, 4 and 13; NE 2, 5 and 8). One interviewee said 'At present we have $100 \%$ of our [TSP program graduates] doing postgraduate emergency nursing education ... because they get credit [into the postgraduate program]' (NM 4).

\section{Transition to Specialty Practice Program (Emergency Nursing) Framework}

Based on the results (above) and the education, nursing practice and safety and quality standards, the development of the TSP (Emergency Nursing) Framework will be presented in the following section. The aim of the TSP (Emergency Nursing) is to facilitate participants' development of foundational knowledge and clinical skills required to practice safely and effectively as beginning emergency nurses. The TSP (Emergency Nursing) was designed to meet the requirements of Level 8 of the $\mathrm{AQF}$, to enable formal articulation to postgraduate study at Graduate Certificate level. The learning outcomes, duration and assessments have been developed to meet this standard and reflect synthesis, critical analysis, evaluation and understanding of advanced theoretical and technical content (AQFC, 2013). The broad outline for this program is presented in Table 2 and further detail is presented below.

Graduates of the TSP (Emergency Nursing) should be able to provide safe, evidencebased nursing care for patients with moderate illness or injury in the ED. It is vital that clinical expectations are congruent with the level of educational and clinical preparation of TSP program participants. Clarity about the end-point of programs also has important patient safety implications given concerns of Nurse Educators and evidence that inexperienced or illprepared nurses place patients at risk of harm and reduce the quality of patient care (KendallGallagher et al. 2011).

Participants will be expected to perform at a proficient level (Benner 1984) for the learning outcomes presented in Table 3, adapted from the CENA Practice Standards (CENA, 2013). Implicit in these learning outcomes is the expectation that participants will practice in accordance with the Registered Nurse Standards for Practice (Nursing and Midwifery Board of Australia 2016) and the National Safety and Quality Health Service Standard (Australian Commission on Safety and Quality in Health Care 2011).

Based on the results from this national study, TSP (Emergency Nursing) participants must be RNs with at least one year of post-registration nursing experience. TSP programs are 
designed to prepare novice emergency nurses for practice in the specialty. TSP programs cannot and should not, replace a graduate nurse program, as a busy ED with an undiagnosed and unstable population is not a suitable environment for newly graduated RNs to consolidate their fundamental nursing skills. This study found that EDs did not adjust the expected endpoint for inexperienced RNs and the TSP (Emergency Nursing) end-point is unlikely to be achieved by a new graduate nurse within the six-month timeframe.

The findings from this study indicate that TSP (Emergency Nursing) participants should be employed in groups of 4-6 participants when ED size and nursing roster vacancy allows, to increase the sense of camaraderie and peer support. The optimal duration for the program is six months. In addition to optimal participant outcomes, offering programs of six months duration was reported to have workforce advantages, enabling EDs to offer two intakes per year if required without a substantial increase in Nurse Educator workload.

The results in this study support that participants should work a minimum of 48 hours per fortnight to enable clinical application of knowledge through practice and repeated experiences (Benner 1984). There should be 40 hours of study days (lectures, workshops, simulation) and additional self-directed work within the TSP program. Additionally, ten days of clinical preparation time should be provided to each participant to enable Nurse Educators to support and assess participants in the clinical setting and enable participants to clinically progress, providing care for patients with moderate illness or injury by completion of the TSP program. The duration and prescribed workload in this framework correspond with the best professional development outcomes identified in this study and are in keeping with the AQF Graduate Certificate (Level 8) volume of learning (AQFC, 2013) therefore enabling formal articulation to postgraduate study. In addition, the workload prescribed in this framework is sufficient for graduates to achieve the learning outcomes (AQFC, 2013). The core content included in the TSP (Emergency Nursing) Framework was informed by data from this study regarding the minimum skills and knowledge delivered in an emergency nursing TSP program and the CENA Practice Standards (2013) (Table 4).

Compulsory clinical assessments that demonstrate structured patient assessment and evidence-based management of a variety of patient presentations across population groups should be completed by participants. Clinical assessments will measure participants' ability to plan and provide high quality care and facilitate feedback and clinical progression. Clinical assessments also enable Nurse Educators to observe non-clinical skills fundamental to safety and quality of care, such as communication, leadership and ethical conduct. Repeated clinical 
assessments were reported in this study to enable Nurse Educators to track performance over time.

This study found that optional written assessments should be offered for participants who choose to apply for formal articulation to postgraduate study. Written assessments are fundamental to formal articulation to postgraduate study in emergency nursing via credits for recognition of prior learning. Recognition of prior learning agreements take into account the comparability of assessment approaches (AQFC, 2013). It is therefore important that the written assessment is equivalent both in complexity and length to those completed by students in nursing Graduate Certificate units (AQF Level 8). As such, written assessments must be of scholarly quality, evidence-based, appropriately referenced and demonstrate deep learning and higher order thinking.

\section{DISCUSSION}

Emergency nursing TSP programs address a major gap between graduate nurse programs and postgraduate study, but have not been subject to the same levels of scrutiny or governance, resulting in variability in TSP program processes and graduate outcomes. The TSPs examined in this study had a positive effect on participant professional development and this finding is supported by the literature (Alban et al. 1999, Considine and Hood 2004, Patterson et al. 2010, Winslow et al. 2009). EDs with TSPs had a significantly higher percentage of Clinical Specialist staff and a higher percentage of postgraduate qualified emergency nurses on the nursing roster than EDs without TSPs. The finding that the TSPs in this study facilitated more rapid clinical progression confirms similar findings reported in the emergency nursing TSP literature (Kidd and Sturt 1995). Other benefits of TSP programs to the emergency nursing workforce, include increased nursing recruitment and retention (Morphet et al. 2011), yet this study shows unwarranted and in some cases detrimental variation in emergency nursing TSP programs. There were several features of TSP programs that were likely to have contributed to the professional development of participants. These included the theoretical content delivered in the TSP; the clinical preparation time and supervision provided to participants; and the TSP peer group which encouraged learning.

The TSP (Emergency Nursing) Framework has been developed based on the findings of this national study of emergency nursing TSP programs and informed by national education and practice standards, to support an evidence based approach to emergency nursing TSP programs that optimises participant and ED workforce outcomes, cost and 
resource use. In light of predicted continued global nursing shortages (Health Workforce Australia 2012), increasing patient demand on EDs (Australian Institute of Health and Welfare 2013) and the results of this large scale national study, hospital executives should use the TSP (Emergency Nursing) Framework as the source of best available evidence to guide the structure, process and outcomes of emergency nursing TSP programs.

In this paper, the development of the TSP (Emergency Nursing) Framework has been detailed. The next step in the development of the emergency nursing workforce is to examine the feasibility of widespread implementation of the TSP (Emergency Nursing) Framework in a range of organisations. Further, the TSP (Emergency Nursing) Framework should be tested as an evidence-based quality indicator against which existing TSP programs in emergency nursing can be benchmarked. Finally, the impact of running the TSP (Emergency Nursing) should be investigated both from a patient safety outcome perspective and from an organisational perspective in terms of resource use.

\section{(a) \\ Limitations}

A gap that has not been addressed in this paper and requires consideration is the cost of TSP programs and comparison of program operating costs against fiscal benefits such as retention and quality of care. TSP programs have been reported to increase nursing retention (Betts 2003, Considine and Hood 2004, Gurney 2002, Kingsnorth-Hinrichs 2009, Morphet et al. 2008, Patterson et al. 2010, Winslow et al. 2009, Morphet et al. 2015), which in turn saves expenditure in recruitment of new staff. Retention and professional development of nurses also improves patient outcomes, which may reduce costs associated with nurse sensitive adverse events (for example falls, medication errors, pressure injuries) (Friedman et al. 2011, Kooker and Kamikawa 2011). A detailed economic analysis is urgently needed to determine the real cost of TSP programs and where programs provide a financial advantage to EDs or organisations.

\section{CONCLUSION}

The TSP (Emergency Nursing) Framework has been developed based on best available evidence from a national study. For the first time, there is an evidence-based framework to guide the structure, process and outcomes of emergency nursing TSP programs and enable a standardised approach to the preparation of novice emergency nurses that has 
been designed to optimise participant and organisational outcomes. The next logical step is to embed the TSP (Emergency Nursing) Framework in emergency nursing practice and evaluate its impact on participant, organisational, patient and quality of care outcomes.

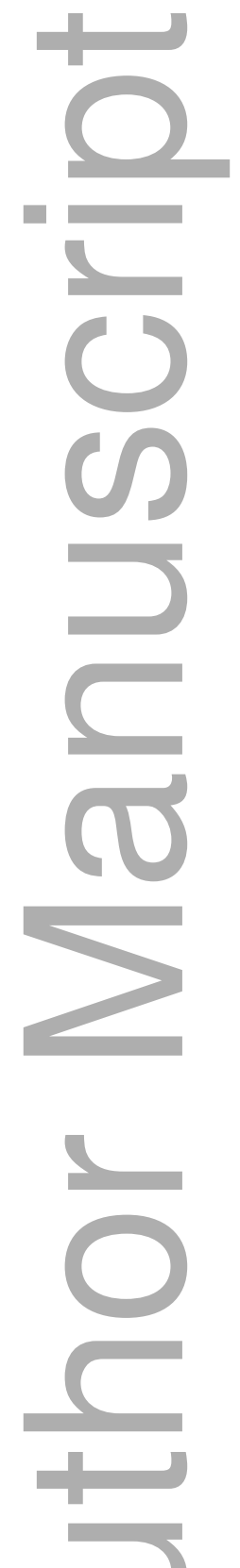

\section{Author Contributions:}

All authors have agreed on the final version and meet at least one of the following criteria (recommended by the ICMJE*):

1) substantial contributions to conception and design, acquisition of data, or analysis and interpretation of data; 
2) drafting the article or revising it critically for important intellectual content.

* http://www.icmje.org/recommendations/

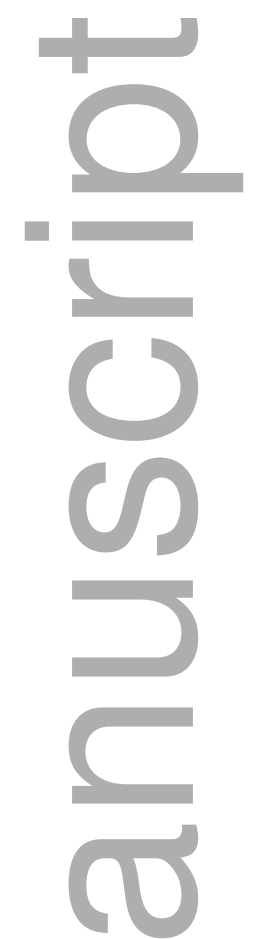

\section{REFERENCES}

Alban, A., Coburn, M. \& May, C. (1999) Addressing the emergency nursing staffing shortage: implementing an internship using a nursing school instructor model. Journal of Emergency Nursing, 25(6), 509-13.

Australian Commission on Safety and Quality in Health Care (2011) National Safety and Quality Health Service Standards. ACSQHC, Sydney.

Australian Health Practitioner Regulation Agency (2015) About the National Scheme. Vol. 2015 AHPRA, Melbourne.

Australian Institute of Health and Welfare (2010) Australian Hospital Statistics 2009-10, Emergency department care and elective surgery waiting times. Canberra.

Australian Institute of Health and Welfare (2011) My Hospitals. Australian Government, Canberra, pp. Annual ED presentations.

Australian Institute of Health and Welfare (2013) Australian Hospital Statistics, 2011-12. Vol. 2013 Canberra, pp. description of peer group definitions.

Australian Qualifications Framework Council (2013) Australian Qualifications Framework. AQFC, South Australia.

Benner, P. (1984) From Novice to Expert: Excellence and power in clinical nursing practice, Addison-Wesley, Sydney. 
Betts, L. (2003) Mentorship. An emergency department recruitment strategy. The Canadian nurse, 99(9), 28-30.

Boyle, M., Butcher, R., Conyers, V., Kendrick, T., MacNamara, M. \& Lang, S. (2008) Transition to intensive care nursing: Establishing a starting point. Australian Critical Care, 21, 190-199.

Brace, N., Kemp, R. \& Snelgar, R. (2003) SPSS for Psychologists, Palgrave Macmillan, New York, USA.

College of Emergency Nursing Australasia (2013) Practice standards for the emergency nursing specialist. CENA, Melbourne.

Considine, J. \& Hood, K. (2004) Career Development Year in emergency nursing: using specific educational preparation and clinical support to facilitate the transition to specialist practice. Nurse Education In Practice, 4(3), 168-176.

Creswell, J. (2009) Research Design; Qualitative, Quantitative and Mixed Methods Approaches, Sage Publications, Singapore.

Donabedian, A. (1988) The quality of care: How can it be assessed? Journal of the American Medical Association, 260(12), 1743-1748.

Friedman, M.I., Cooper, A.H., Click, E. \& Fitzpatrick, J.J. (2011) Specialized new graduate RN critical care orientation: Retention and financial impact. Nursing Economics, 29(1), 7-14.

Glynn, P. \& Silva, S. (2013) Meeting the needs of new graduates in the emergency department: A qualitative study evaluating a new graduate internship program. Journal of Emergency Nursing, 39(2), 173-178.

Gurney, D. (2002) Developing a successful 16-week 'transition ED nursing' program: one busy community hospital's experience. Journal of Emergency Nursing, 28(6), 505-14.

Health Workforce Australia (2012) Health Workforce 2025 - Doctors, Nurses and Midwives. Vol. 1 HWA, Adelaide.

Heath, P. (2002) National Review of Nursing Education 2002. Commonwealth of Australia, Canberra, ACT.

IBM Corporation (2012) Statistical Package for the Social Sciences (SPSS). Armonk, New York, USA.

Jarman, H. \& Newcombe, P. (2010) Support for nurses who are new to emergency care. Emergency Nurse, 17(9), 16-19. 
Kendall-Gallagher, D., Aiken, L.H., Sloane, D.M. \& Cimiotti, J.P. (2011) Nurse Specialty Certification, Inpatient Mortality and Failure to Rescue. Journal of Nursing Scholarship, 43(2), 188-194.

Kidd, P. \& Sturt, P. (1995) Developing and evaluating an emergency nursing orientation pathway. Journal of Emergency Nursing, 21(6), 521-530.

Kingsnorth-Hinrichs, J. (2009) Growing new graduates... it takes a village. $R N$, 72(1), 40.

Kooker, B.M. \& Kamikawa, C. (2011) Successful strategies to improve RN retention and patient outcomes in a large medical centre in Hawaii. Journal of Clinical Nursing, 20(1-2), 34-39.

Loiseau, D., Kitchen, K. \& Edgar, L. (2003) A comprehensive ED orientation for new graduates in the emergency department: the 4-year experience of one Canadian teaching hospital. Journal of Emergency Nursing, 29(6), 522-7.

Morphet, J., Considine, J. \& McKenna, L. (2011) Transition to specialty practice programs in emergency nursing - A review of the literature. Australasian Emergency Nursing Journal, 14(1), 45-49.

Morphet, J., Kent, B., Plummer, V. \& Considine, J. (2015) The effect of transition to specialty practice programs on Australian emergency nurses professional development, recruitment and retention. Australasian Emergency Nursing Journal, 18(4), 204-211.

Morphet, J., McKenna, L. \& Considine, J. (2008) The career development year: Responding to the emergency nursing shortage in Australia. Australasian Emergency Nursing Journal, 11, 32-38.

National Health Performance Authority (2013) My Hospitals. Vol. 2012 Australian Institute of Health and Welfare, Sydney.

New South Wales Health (2011) Clinical Nurse Consultants - Domains and Functions. NSW Health, Sydney, NSW.

Nursing and Midwifery Board of Australia (2016) Registered Nurse Standards for Practice. NMBA, Melbourne.

Pallant, J. (2013) SPSS Survival Manual, Allen \& Unwin, Sydney, Australia.

Patterson, B., Bayley, E.W., Burnell, K. \& Rhoads, J. (2010) Orientation to emergency nursing: Perceptions of new graduate nurses. Journal of Emergency Nursing, 36(3), 203-211.

Polit, D. \& Beck, C. (eds.) (2014) Essentials of Nursing Research; Appraising evidence for nursing practice, Lippincott Williams \& Wilkins, Sydney, Australia. 
Schneider, Z., Whitehead, D., LoBiondo-Wood, G. \& Haber, J. (2013) Nursing and Midwifery Research; Methods and appraisal for evidence-based practice, Mosby, Elsevier, Sydney, Australia.

Schneider, Z., Whitehead, D., LoBiondo-Wood, G. \& Haber, J. (2016) Nursing and Midwifery Research: Methods and appraisal for evidence based practice Elsevier, Sydney, Australia.

Sweeney, J. (2010) Bayfront ED novice nurse internship program. Journal of Emergency Nursing, 36(2), 173-174.

Teddlie, C. \& Tashakkori, A. (2009) Foundations of mixed methods research: Integrating quantitative and qualitative approaches in the social and behavioural sciences, SAGE Publications, London.

Truman, K. (2004) Education enhances R and R in the ED. Don't eat your young; nurse them. Nursing Management, 35(7), 45-8.

Winslow, S., Almarode, M., Cottingham, S., Lowry, K. \& Walker, K. (2009) New graduates in the emergency department: Could you, would you, should you? Journal of Emergency Nursing, 35(6), 521-524.

Wolf, L. (2005) An ED orientation / fellowship: An experiment in process-oriented training and learnign to think like an emergency nurse. Nurse Educator, 31(3), 298-301.

Zavotsky, K.E. (2000) Developing an ED training program: how to 'grow your own' ED nurses. Journal of Emergency Nursing, 26(5), 504-6.

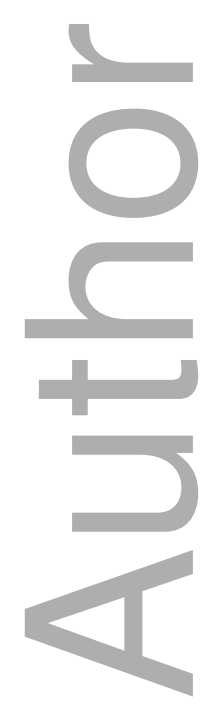


Table 1 - Aims \& Characteristics of Emergency Nursing Transition to Specialty Practice Programs

\begin{tabular}{|c|c|c|c|c|c|}
\hline Study & Country & Program Aims & $\begin{array}{l}\text { Target } \\
\text { Participants }\end{array}$ & Model & $\begin{array}{l}\text { Course Duration } \\
\text { (months) }\end{array}$ \\
\hline Alban et al. (1999): & US & $\begin{array}{l}\text { i) recruitment } \\
\text { ii) retention } \\
\text { iii) preparation for practice }\end{array}$ & $\mathrm{RN}$ & Theoretical preparation & 6 \\
\hline Betts (2003). & Canada & $\begin{array}{l}\text { i) retention } \\
\text { ii) improve staff morale }\end{array}$ & $\mathrm{RN}$ & Preceptorship & 9 \\
\hline Considine \& Hood (2004) & Australia & $\begin{array}{l}\text { i) recruitment } \\
\text { ii) retention } \\
\text { iii) preparation for practice }\end{array}$ & $\mathrm{RN}$ & Theoretical preparation & 12 \\
\hline Glynn (2013). & US & i) preparation for practice & NGN & $\begin{array}{l}\text { Theoretical preparation / } \\
\text { preceptorship }\end{array}$ & 4 \\
\hline Gurney (2002). & US & i) recruitment & NGN & $\begin{array}{l}\text { Theoretical preparation / } \\
\text { Preceptorship }\end{array}$ & 5 \\
\hline Jarman \& Newcombe (2010). & UK & i) preparation for practice & RN \& NGN & $\begin{array}{l}\text { Theoretical preparation / } \\
\text { Preceptorship }\end{array}$ & NA \\
\hline Kidd \& Sturt (1995). & US & $\begin{array}{l}\text { i) retention } \\
\text { ii) preparation for practice }\end{array}$ & RN \& NGN & Preceptorship & $1-2$ \\
\hline Kingsnorth-Hinrichs (2009). & US & i) preparation for practice & NGN & $\begin{array}{l}\text { Theoretical preparation / } \\
\text { Preceptorship }\end{array}$ & 24 \\
\hline Loiseau, Kitchen \& Edgar (2003). & Canada & $\begin{array}{l}\text { i) recruitment } \\
\text { ii) retention } \\
\text { iii) preparation for practice }\end{array}$ & NGN & $\begin{array}{l}\text { Theoretical preparation / } \\
\text { Preceptorship }\end{array}$ & 4 \\
\hline $\begin{array}{l}\text { Morphet, McKenna \& Considine } \\
\text { (2008). }\end{array}$ & Australia & $\begin{array}{l}\text { i) recruitment } \\
\text { ii) retention } \\
\text { iii) preparation for practice }\end{array}$ & $\mathrm{RN}$ & Theoretical preparation & 12 \\
\hline
\end{tabular}

This article is protected by copyright. All rights reserved 


\begin{tabular}{|c|c|c|c|c|c|}
\hline Study & Country & Program Aims & $\begin{array}{l}\text { Target } \\
\text { Participants }\end{array}$ & Model & $\begin{array}{l}\text { Course Duration } \\
\text { (months) }\end{array}$ \\
\hline Patterson et al. (2010). & US & i) preparation for practice & RN \& NGN & $\begin{array}{l}\text { Theoretical preparation / } \\
\text { Preceptorship }\end{array}$ & 6 \\
\hline Sweeney (2010). & US & $\begin{array}{l}\text { i) recruitment } \\
\text { ii) preparation for practice }\end{array}$ & $\mathrm{RN}$ & $\begin{array}{l}\text { Theoretical preparation / } \\
\text { Preceptorship }\end{array}$ & $3-4$ \\
\hline Truman (2004). & US & i) preparation for practice & NGN & $\begin{array}{l}\text { Theoretical preparation / } \\
\text { Preceptorship }\end{array}$ & 6 \\
\hline Winslow et al. (20 & US & $\begin{array}{l}\text { i) retention } \\
\text { ii) preparation for practice }\end{array}$ & NGN & $\begin{array}{l}\text { Theoretical preparation / } \\
\text { preceptorship }\end{array}$ & 6 \\
\hline Wolf (2005). & US & i) preparation for practice & NGN & $\begin{array}{l}\text { Theoretical preparation / } \\
\text { preceptorship }\end{array}$ & 4 \\
\hline Zavotsky (2000). & US & $\begin{array}{l}\text { i) recruitment } \\
\text { ii) preparation for practice }\end{array}$ & & $\begin{array}{l}\text { Theoretical preparation / } \\
\text { Preceptorship }\end{array}$ & 2.5 \\
\hline
\end{tabular}

Note. US = United States; UK = United Kingdom; RN = Registered Nurse; NGN = newly graduated nurse; NA = not reported.

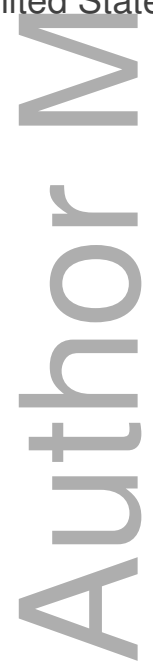

This article is protected by copyright. All rights reserved 
Table 2 - Transition to Specialty Practice (Emergency Nursing) Framework

\section{STRUCTURE}

Underpinned by Novice to Expert model of skill acquisition (Benner, 1984)

Participants - novice emergency Registered Nurses with $\geq 1$ year nursing experience

Groups of $4-6$ participants

\section{PROCESS}

6 months duration

Participants employed $\geq 0.6$ FTE (536 hours of clinical practice over a six month period)

40 hours of study days

40 hours self-directed work

10 days clinical preparation

Structured clinical patient assessments

Optionalwritten assessments

\section{OUTCOME}

Proficient to care for emergency department patients with moderate illness or injury

Proficient in practice within the following domains:

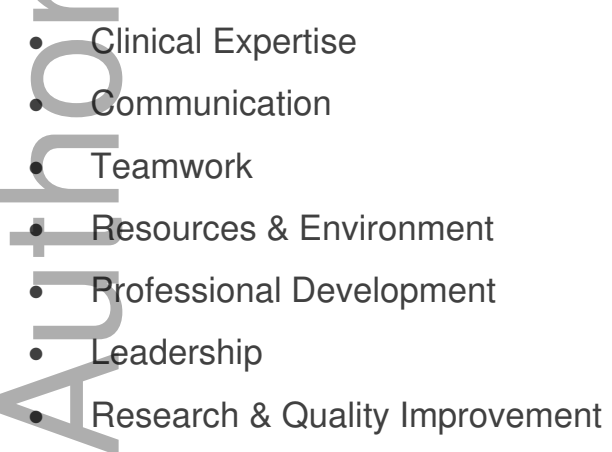

Articulation to postgraduate study in emergency nursing 
Note. $\mathrm{FTE}=$ full time equivalent

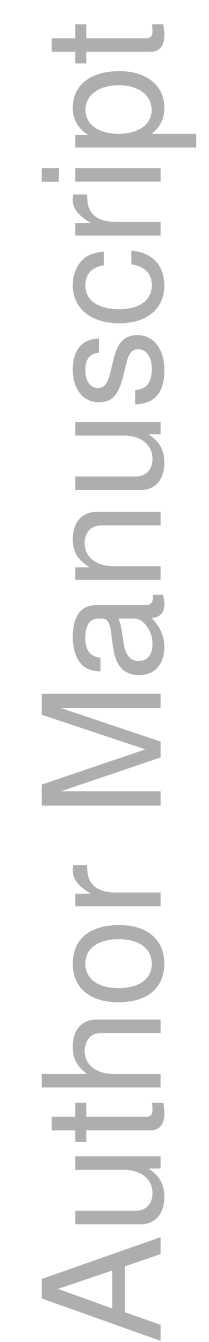

This article is protected by copyright. All rights reserved 
Table 3 - Transition to Specialty Practice (Emergency Nursing) learning outcomes

\section{Domain 1 - Clinical Expertise}

1.1 Provides a concise and timely assessment of the undiagnosed patient; ${ }^{1,2}$

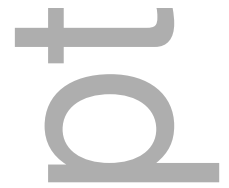

1.2 Anticipates and instigates appropriate treatment and management strategies for multiple undifferentiated patients within a dynamic environment; ${ }^{1}$

1.3 Evaluates patient progress against predicted outcomes; ${ }^{1,2}$

1.4 Demonstrates the ability to coordinate the admission and/or discharge of patients with a variety of clinical needs; ${ }^{1}$

1.5 Demonstrates the ability to provide patient and family-centred care. ${ }^{1,2}$

\section{Domain 2 - Communication}

2.1 Provides effective communication with all members of the health care teams and external agencies; ${ }^{1,2}$

2.2 Communicates effectively with patient, family and support people. ${ }^{1,2,3}$

\section{Domain 3 - Teamwork}

3.1 Performs effectively as a team member; ${ }^{1,2}$

3.2 Provides effective timely direction and supervision to ensure safe, quality patient care; ${ }^{1,3}$

3.3 Appropriately manages critical incidents and stressful situations at an advanced beginner level. ${ }^{1}$

\section{Domain 4 - Resources \& Environment}

4.1 Practises to promote \& maintain patient and staff safety, ${ }^{1,2}$

4.2 Effectively anticipates \& provides appropriate human resources to promote optimal patient care; ${ }^{1}$

4.3 Utilises and manages material resources effectively and responsibly to promote optimal patient care at a competent level; ${ }^{1}$

4.4 Demonstrates an understanding of the ED disaster management plans, familiar with location of equipment used in major incidents.

\section{Domain 5 - Professional Development}

5.1 Maintains own professional development, ${ }^{1,2}$

5.2 Contributes to the professional development of emergency nursing colleagues: ${ }^{1,2}$

5.3 Promotes the specialty of emergency nursing. ${ }^{1}$

\section{Domain 6 - Leadership}

6.1 Demonstrates leadership that enables positive role modelling for nursing and other health professionals; $;^{1,2}$

6.2 Able to safely lead a team in caring for the at-risk patient at an 
advanced beginner level..$^{3}$

\section{Domain 7 - Legal}

7.1 Complies with prevailing legislation and standards of best practice.$^{1,2}$

\section{Domain 8 - Professional Ethics}

8.1 Functions within an ethical framework. ${ }^{1,2}$

Domain 9-Research \& Quality Improvement
9.1 Demonstrates support for quality improvement within the emergency
care environment, ${ }^{1,23}$
9.2 Utilises and supports the development of research within the
emergency care environment. ${ }^{1}$

1 College of Emergency Nursing Australasia Professional Practice Standards, 2013

2 Nursing and Midwifery Board of Australia, 2016

3 Australian Commission on Safety \& Quality in Health Care, 2011.
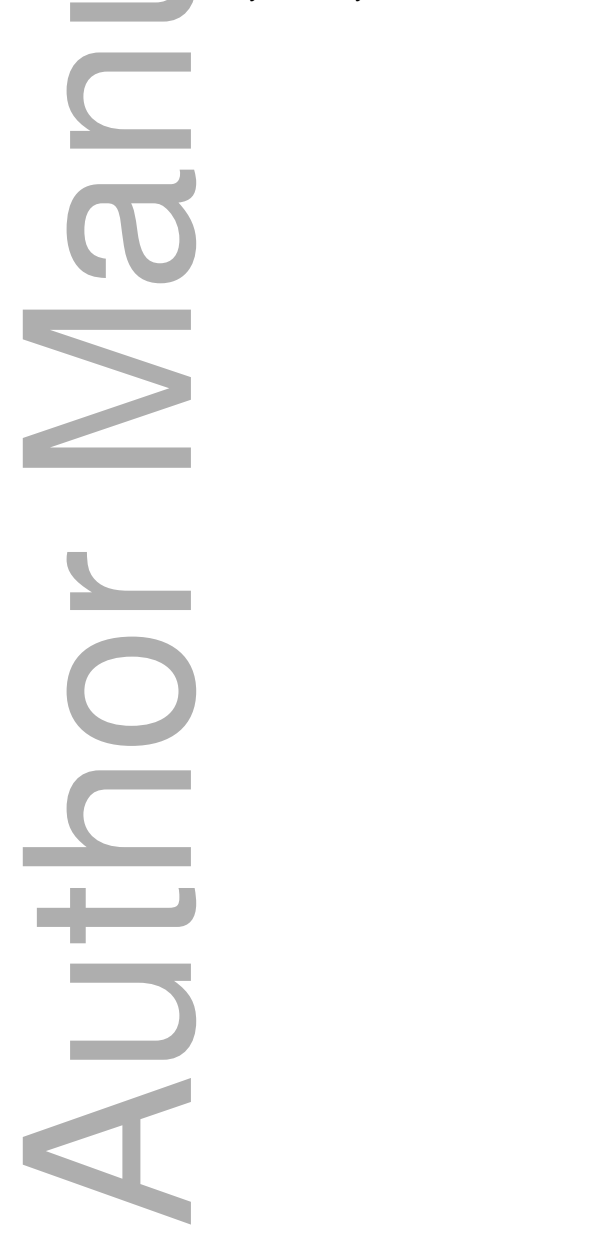

This article is protected by copyright. All rights reserved 
Table 4 - Core content for the Transition to Specialty Practice (Emergency Nursing)

Advanced Life Support

Cardiac emergencies, including chest pain management

ECG interpretation - sinus rhythm, sinus tachycardia, sinus bradycardia, ST elevation, ST depression, atrial fibrillation, atrial flutter, supra-ventricular tachycardia (SVT), asystole, ventricular tachycardia (VT), ventricular fibrillation (VF)

Communication with patients, families and healthcare team

Endocrine emergencies

Gastrointestinal emergencies

Mental health emergencies

Neurological emergencies

Pain assessment and management

Pharmacology

Predictors of patient deterioration

Principles of trauma management

Quality and safety in healthcare

Recognising and responding to clinical deterioration

Renal emergencies

Respiratory emergencies

Shock

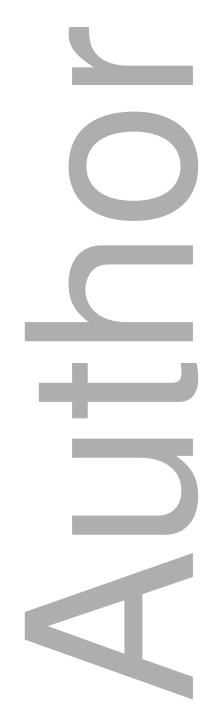

This article is protected by copyright. All rights reserved 


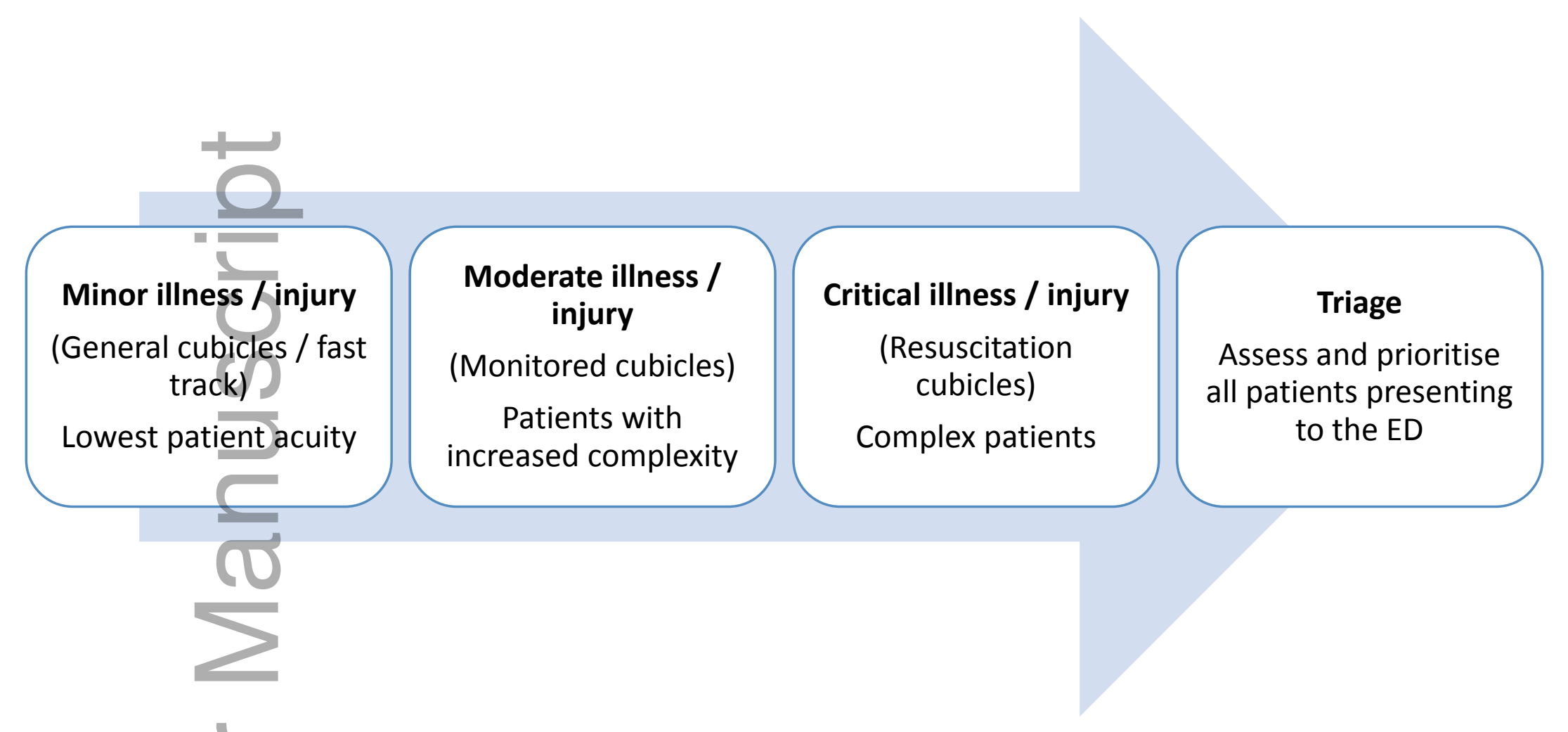

Figure 1 The process of clinical progression for emergency nurses

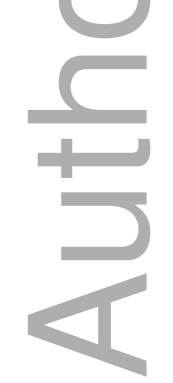




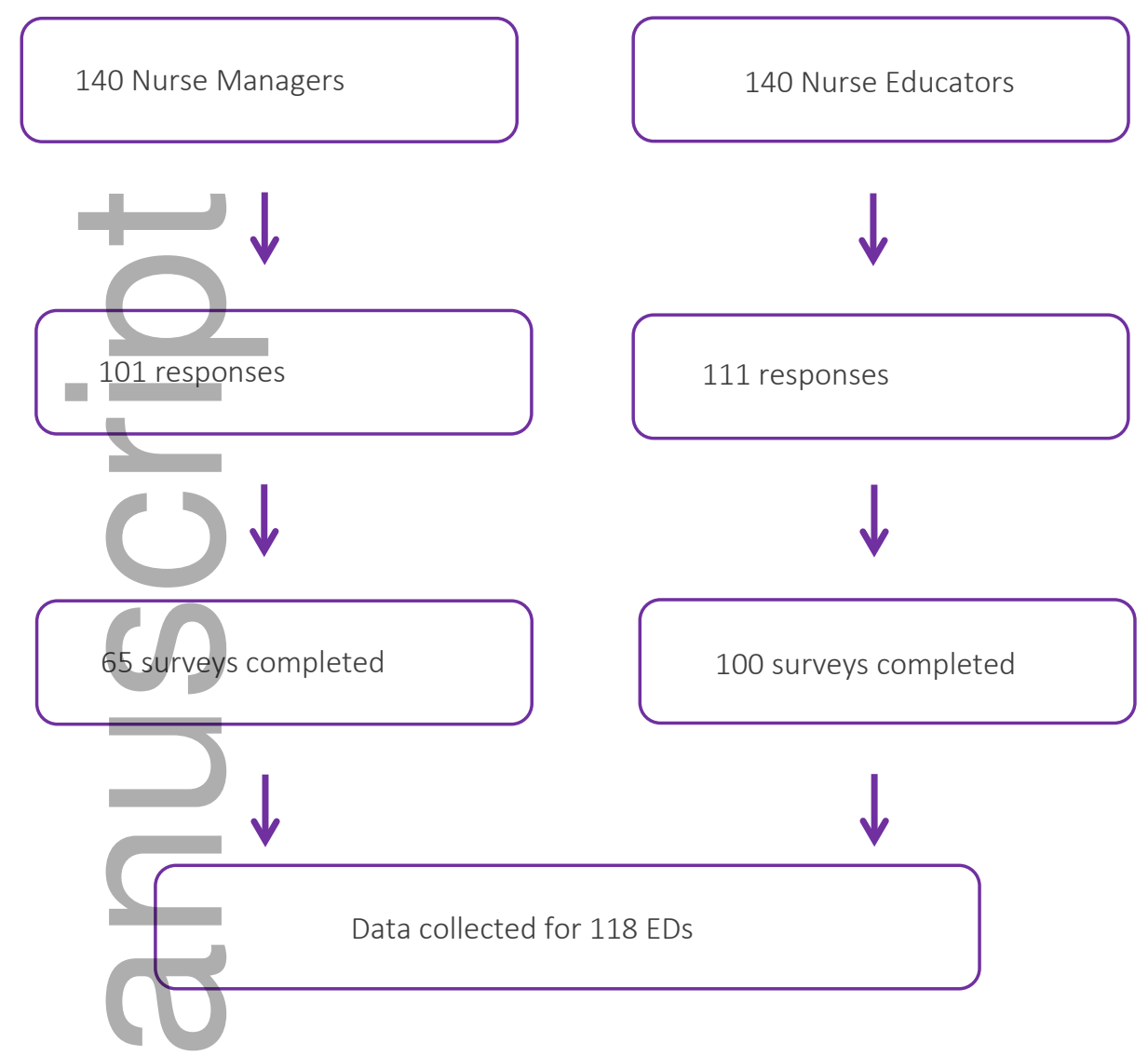

Figure 2 Survey response flow chart 


\section{University Library}

\section{- M M I E E R VA A gateway to Melbourne's research publications}

Minerva Access is the Institutional Repository of The University of Melbourne

Author/s:

Morphet, J;Plummer, V;Kent, B;Considine, J

Title:

A framework for transition to specialty practice programmes.

Date:

2017-08

Citation:

Morphet, J., Plummer, V., Kent, B. \& Considine, J. (2017). A framework for transition to specialty practice programmes.. J Adv Nurs, 73 (8), pp.1970-1981. https://doi.org/10.1111/ jan.13279.

Persistent Link:

http://hdl.handle.net/11343/292662 